\section{Pattern analysis of visible faulty fruits in capitula: A case in cultivated sunflower (Helianthus annuus L.)}

\author{
Luis F. Hernández ${ }^{1,2}$ \\ Cecilia N. Pellegrini ${ }^{3}$
}

${ }^{1}$ Laboratory of Plant Morphology, Department of Agronomy, Universidad Nacional del Sur, Bahía Blanca; ${ }^{2}$ Commission of Scientific Investigations of the Province of Buenos Aires, La Plata; ${ }^{3}$ Apicultural Studies Laboratory, Department of Agronomy, Universidad Nacional del Sur, Bahía Blanca, Argentina

\section{Abstract \\ The analysis of spatial arrangement of} incompletely developed fruits (IDF) in capitula could be used to understand the nature and the relative arrangement of these fruits at maturity, previously unexplained by current models. The objective of this work was to quantify and define the distribution pattern of visible IDF ( IDF $\left._{\text {vis }}\right)$ at physiological maturity in the capitulum of the cultivated sunflower, in two genotypes with different self-compatibility expression grown in three different environments. Spatial characteristics and the possibility of randomness of $\mathrm{IDF}_{\mathrm{vis}}$ pattern generation were also evaluated. We were able to define four IDF $_{\text {vis }}$ patterns: Type I, where the distribution of the IDF $_{\text {vis }}$ was located mainly at the capitulum center, Type II, where the distribution remained grouped at its center but spreads towards the periphery, Type III, where the distribution was more homogeneous over the entire capitulum surface and Type IV with a homogeneous but very dispersed distribution over the entire capitulum surface. Second order spatial point pattern analysis techniques for a plane (Ripley's K) were applied to the distribution of $\mathrm{IDF}_{\mathrm{vis}}$ in the four predefined $\mathrm{IDF}_{\mathrm{vis}}$ patterns. Using the $A D E-4$ software, spatial distribution patterns contained in a circular surface and corrected for edge effects were analyzed. By grouping the different types of $\mathrm{IDF}_{\text {vis }}$ patterns by environment and genotype, a tendency was observed to generate preferably two types of patterns, Type I and Type IV, directly related to the genotype and not to the environment. The $\mathrm{K}$ index obtained for each type of pattern showed that, for the scales analyzed, Types I, II and III can be defined as grouped, since they laid outside the Poisson confidence limits.
The Type IV pattern presented results consistent with a completely randomized distribution. It was observed a low- frequency appearance of the IV (random) pattern and only for one genotype in the different environments studied, while in the rest of the genotype $\mathrm{x}$ environment combinations there was always a greater degree of grouping (non random; Type; I, II and III patterns). Proved that mostly of the IDF $_{\text {vis }}$ patterns presented in the sunflower capitulum were mainly non random, the results shown here suggest that, to the intrinsic characteristics of the plant to express this character, mainly physiological, intra-receptacle physical factors could be added in the post-pollination stage, capable of altering the normal development of the embryos.

\section{Introduction}

At maturity, the head (capitulum) of cultivated sunflower [Helianthus annuus L. var. macrocarpus (D.C.) Ckll.] in both selfsterile and self-fertile cultivars usually show a set of fruits with an arrested pericarp (hull) and/or embryo/seed development. In normal fruits, the seed fills the entire cavity of the ovary (fully developed fruits or FDF). ${ }^{1}$ On the other hand, mostly mature ones often contain and ovule that did not fully develop into seed. In those fruits, seed growth has stopped at different moments, leaving the fruit with an incompletely developed pericarp and/or seed. These fruits are considered as "seedless" or "empty" and were defined as incompletely developed or IDF. ${ }^{1}$

Some IDF with fully developed pericarp are not distinguishable on the mature capitulum surface. We only can discriminate them after weighing or by finger compressing once they were harvested. However, other IDF are easily identified over the capitulum surface, ${ }^{1,2}$ because the pericarp sometimes is light stained and compressed by neighboring fruits showing an external collapsed appearance. So, we extend the classification to "visible" IDF $\left(\mathrm{IDF}_{\text {vis }}\right.$; Figure 1).

The origin of IDF could be attributed to lack of pollination or post pollination failures as well as environmental, mechanical, physiological and/or anatomical causes during the early development of embryos. ${ }^{3-7}$ Also we can include vascular deficiencies at the ovary-receptacle interphase, the competition for resources between the developing ovaries or mechanically-induced abortion. ${ }^{7-}$ 11 We usually can find IDF $_{\text {vis }}$ at the capitulum center but in many cases they can be located all over the capitulum. In the sunflower production as in many other species,
Correspondence: Luis F. Hernández, Laboratorio de Morfología Vegetal, Departamento de Agronomía, Universidad Nacional del Sur. Bahía Blanca, 8000, Argentina.

Tel.: +54.0291.4617647.

E-mail: 1fhernandez@uns.edu.ar

Key words: Sunflower, Helianthus annuus L., capitula, fruit pattern, point pattern analysis.

Contributions: The authors contributed equally.

Conflict of interest: the authors declare no potential conflict of interest.

Funding: This work was supported by grants to L.F. Hernández of the Secretaría General de Ciencia y Tecnología (SeGCyT) of the UNSur and the Comisión de Investigaciones Científicas (CIC, La Plata) Argentina.

Received for publication: 20 September 2019. Accepted for publication: 1 October 2019.

This work is licensed under a Creative Commons Attribution-NonCommercial 4.0 International License (CC BY-NC 4.0).

${ }^{C}$ Copyright: the Author(s), 2019

Licensee PAGEPress srl, Italy

International Journal of Plant Biology 2019; 10:8317 doi:10.4081/pb.2019.8317

the number of harvestable fruits per plant is one of the main yield components. ${ }^{5}$ So, IDF are one of the causes of important reductions in its yield. ${ }^{12-15}$

Although some studies have investigated relationship between fruit set and withininflorescence spatial position (proximal, intermediate and distal), unfortunately, to our knowledge, there is no report in literature concerning the fruit setting patterns in capitula.

In a previous work, ${ }^{2}$ it was found a good correlation $\left(R^{2}=0.63-0.81\right)$ between the number of total IDF per contact parastichy and the number of IDF $_{\text {vis }}$ per capitulum. So, $\mathrm{IDF}_{\mathrm{vis}}$ setting pattern could be used to study the underlying physiological and/or morphological mechanisms and to identify the nature and the relative arrangement of these fruits at maturity previously unexplained by other models' proposals. ${ }^{16}$

The study of IDF $_{\text {vis }}$ patterns would allow us to focus towards other variables other that the capitulum available space. ${ }^{17}$ The relative proportion of $\mathrm{IDF}_{\mathrm{vis}}$ in the capitulum varies according to the genotype and the environmental conditions in which the crop grows. ${ }^{1,2}$ Also the existence of a positive correlation between bee visitation on the sunflower capitulum at flowering 
stage and IDF $_{\text {vis }}$ generation, ${ }^{18}$ gave us a hint about the possibility of randomness of total IDF generation. So, defining if $\mathrm{IDF}_{\mathrm{vis}}$ patterns are aggregated and ordered or on the other hand are scattered or at random, would allow to discard or accept different causalities of this phenomenon and in this way it will enable us to approach further studies more efficiently.

The objective of this work was to define the distribution pattern of IDF $_{\text {vis }}$ in the sunflower capitulum at physiological maturity, in genotypes with different self-compatibility expression grown in different environments, and to establish the relationship between the total IDF and their relative position in the capitulum. Spatial characteristics and the distribution of IDF $_{\text {vis }}$ were then evaluated, considering a surface in which patterns are presented by chance or are conditioned to some unknown intrinsic or extrinsic factor.

\section{Materials and Methods}

Two commercial sunflower genotypes named in this work for confidentiality reasons as "Hybrid A" (medium self-compatibility) and "Hybrid B" (low self-compatibility), provided by Dekalb Seeds of Argentina, with different genetic background and different susceptibility to generate IDF were used. ${ }^{19}$

Plants were grown under field conditions at a density of 6.0 plants $\mathrm{m}^{-2}$ on a randomized block design. Trials were conducted during 3 consecutive years in 3 different agro-ecological sites in southern Argentina: Colorado river valley ( $\mathrm{Vil}$, furrow-irrigated, Lat. S. $39^{\circ} 55^{\prime}$, Long. W. $62^{\circ} 40^{\prime}$ ); Bahía Blanca (UNS experimental field -Bai, drip irrigation, Lat. S. $38^{\circ} 45^{\prime}$, Long. W. $62^{\circ} 11^{\prime}$ ) and Tres Arroyos (Barrow Experimental Station -Tar, dry land cultivation, Lat. S. $38^{\circ} 20^{\prime}$, Long. W. $60^{\circ} 13^{\prime}$ ) all of them under appropriate fertilization and sanitary conditions.

Plants were exposed to open pollination, and bee counts per capitulum were performed to ensure the presence of vectors during flowering. At physiological maturity $(\mathrm{PM}),{ }^{20} 30$ capitula per site and genotype were randomly harvested from the crop lots. Each capitulum was considered an experimental unit.

Identification of $\mathrm{IDF}_{\mathrm{vis}}$ in the capitulum

In the laboratory $\mathrm{IDF}_{\text {vis }}$, with the external appearance of weak pericarp, undeveloped, flattened and lighter in color than the surrounding ones, (categories I and II) ${ }^{21}$ were identified on the surface of each capit- ulum (Figure 1). On top of each harvested capitulum a transparent acetate sheet was fixed and the relative position of all the $\mathrm{IDF}_{\text {vis }}$ (Figure $1 \mathrm{~b}$ ), was marked using a permanent ink pen. The dot pattern for each acetate sheet was digitized and the Cartesian coordinates for each "dot" = IDF in a circular surface were obtained using appropriate software (GetData Graph Digitizer vers. 2.26; http://getdata-graphdigitizer.com). Each coordinate was cor- rected by position and diameter of the capitulum. So, for each individual pattern, the circular surface was considered equivalent for all of them (Figure 2).

\section{Definition of IDF $_{\text {vis }}$ patterns}

After the identification of $\mathrm{IDF}_{\mathrm{vis}}$ in all sampled capitula we were able to define four patterns of reference (Figure 2): Type I, where the distribution of the $\mathrm{IDF}_{\mathrm{vis}}$ were grouped mainly at the capitulum center
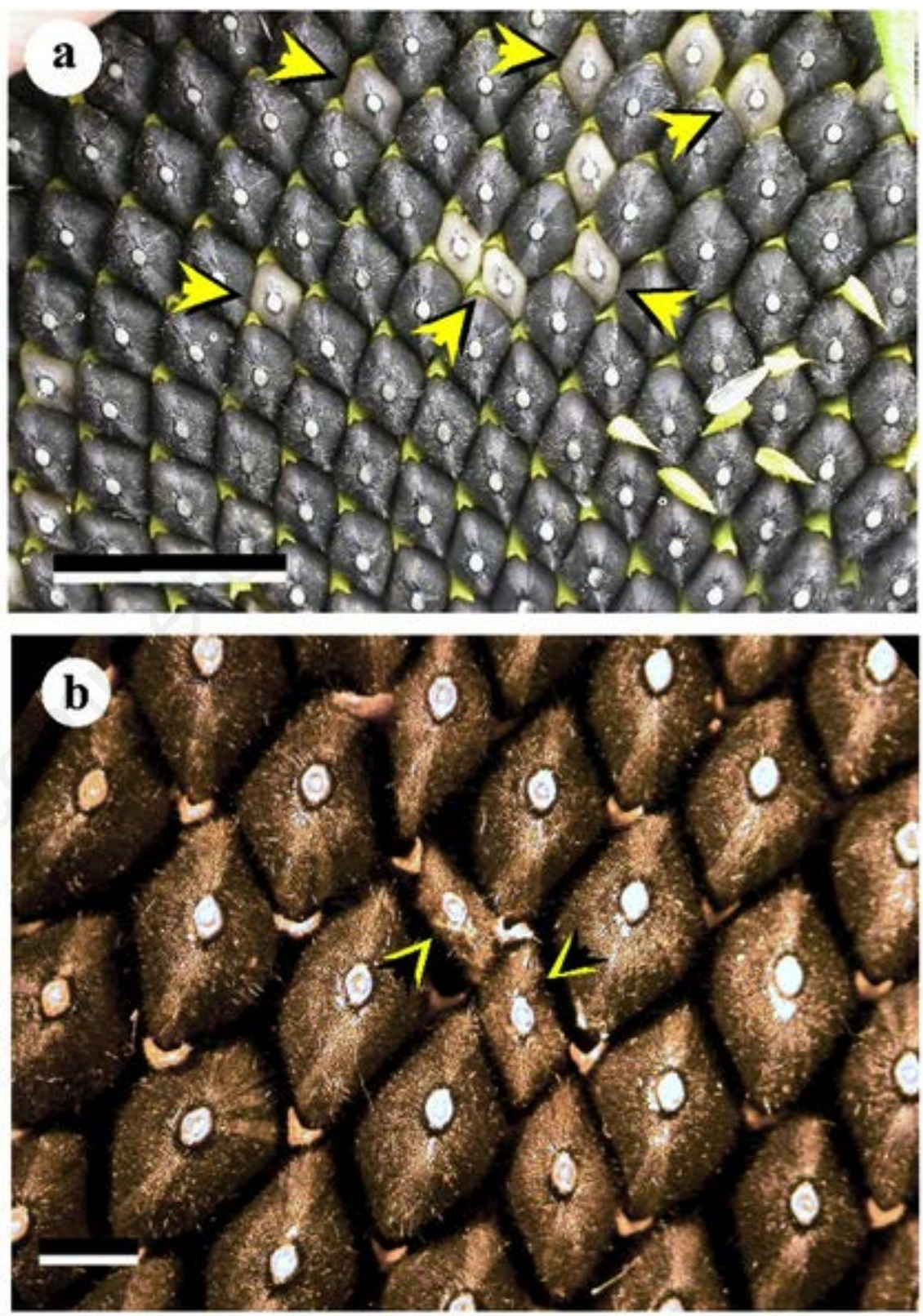

Figure 1. a) Peripheral region of the sunflower capitulum at reproductive stage (RS) 6-7, [27], showing delayed developed fruits (arrows), surrounded by advanced developed fruits. b) The same region of Fig. 1A at RS9, (physiological maturity ${ }^{2}$ ). Arrows indicate the location of the pre-defined IDF $_{\text {vis }}$ observed in Fig. 1A. Note the marked fruits with smaller and lighter colored or darker but compressed pericarps in comparison with those surrounding them. IDFvis: visible incompletely developed fruits. The scale bar for both figures is $1 \mathrm{~cm}$. 
(Figure 2a), Type II, where the distribution remained grouped at its center but expands towards its periphery (Figure 2b), Type III, where the distribution was more homogeneous over the entire capitulum surface (Figure 2c) and Type IV with a homogeneous but very dispersed distribution over the entire capitulum surface (Figure 2d).

\section{Spatial analysis of IDF $_{\text {vis }}$ patterns}

On the distribution for the four predefined $\mathrm{IDF}_{\mathrm{vis}}$ patterns for each genotype, location and capitulum, second order spatial point pattern analysis techniques (Ripley's $\mathrm{K})^{22}$ of points in the plane were carried out (coefficient K), ${ }^{22}$ following what was described in Thioulouse et al. ${ }^{23}$ It was studied using the $A D E-4$ software, ${ }^{24}$ using the complete spatial module. ${ }^{23}$ The spatial distribution patterns contained in a circular surface and corrected for edge effects were analyzed. ${ }^{25}$

\section{Theoretical background of the methodology used}

A widely used spatial statistic of point pattern analysis is Ripley's K(t), a univariate second-order analysis of point patterns in a two-dimensional space. ${ }^{26,27}$ The term "second order" refers to the analysis of all point-to-point distances, as opposed to firstorder analyses such as "nearest neighbor" that use only the mean of interpoint distances. ${ }^{26,27}$ With Ripley's analysis, a circle of radius $t$ is centered at each spatial data point and the number of neighbors within the circle is counted. ${ }^{27}$

The $\mathrm{K}(\mathrm{t})$ function gives the expected number of points within radius $t$ of an arbitrary point under a prescribed distribution. ${ }^{27}$ If points are randomly distributed (following a Poisson distribution), then the expected value will not exceed a fixed threshold (Figure 3). ${ }^{27}$

Confidence intervals were calculated for this expected value using Monte Carlo simulations. ${ }^{28}$ Simulations entail randomly generating points for plots of the same size as the observed plot, with the lowest and highest values of $\mathrm{K}(t)$ for each $\mathrm{t}$ used to estimate the lower and upper bounds of confidence envelopes. ${ }^{27}$ If the expected value for any size-step exceeds the value established by the confidence envelopes, then the null hypothesis of spatial randomness is rejected for that value of $t$ (Figure 3). ${ }^{27,29}$

To achieve a 99 percent confidence interval, 99 simulations must be calculated. ${ }^{29}$ So, 99 random patterns were generated (Figure 2e) and the L-function analysis was run on all of them. In order to work on a secure basis of randomness, computer graphics software was used. ${ }^{21}$ It allowed obtaining random patterns of $\mathrm{IDF}_{\mathrm{vis}}$ on arti- ficially generated capitula. A random point generation routine was included so, when the program generates a coordinate point where the fruit is going to be located, at random it is considered "on" or "off". The highest and lowest $L$ values for each $r$ value were the taken and used those to generate the confidence envelopes. ${ }^{24}$ These confidence envelopes would then take into account both the regular pattern of the florets at a small scale and the circular shape of the sunflower that may cause edge effects. The software details were described in Ripley. $^{21}$
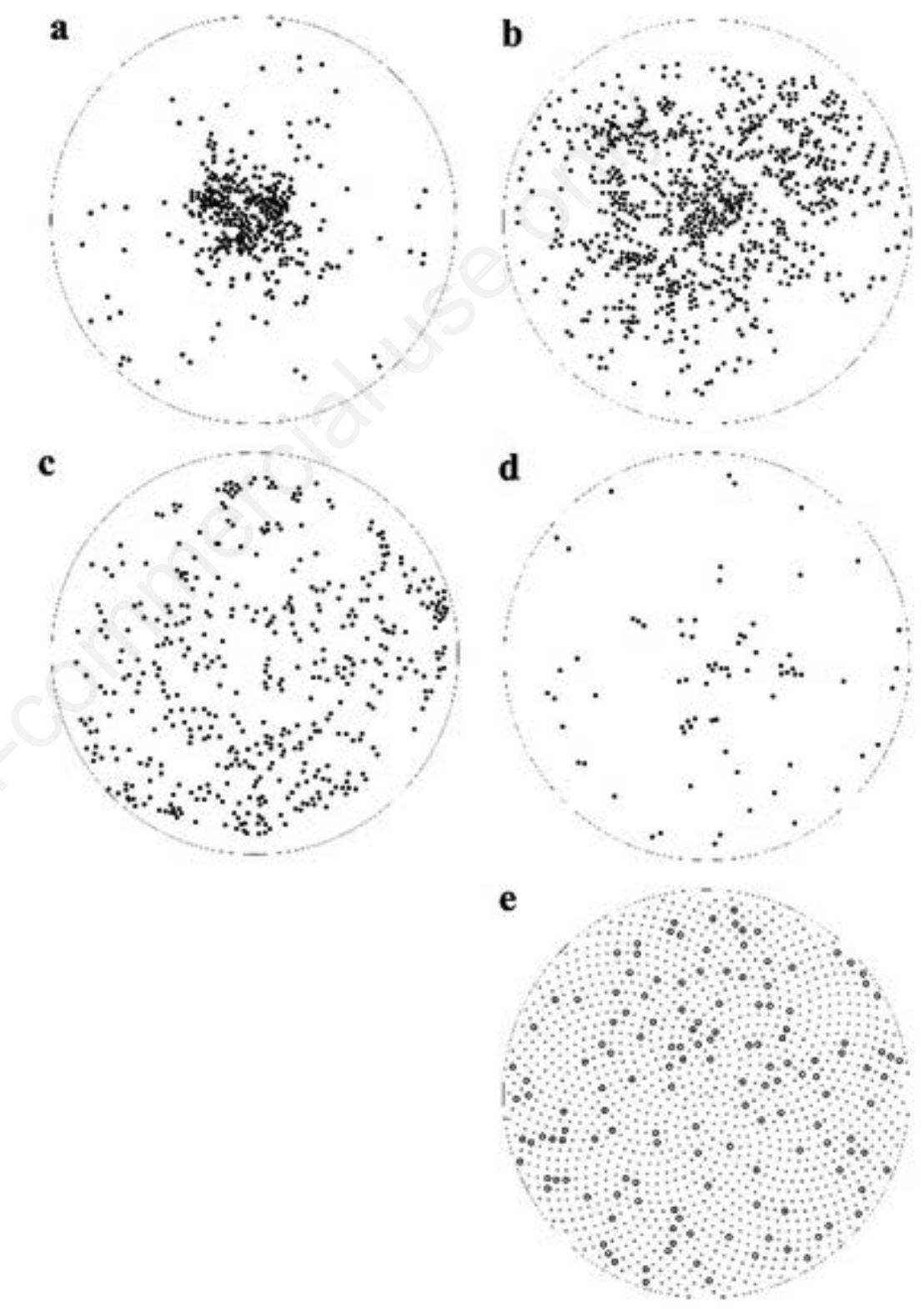

Figure 2. Characteristic patterns of IDFvis identified in the sunflower capitulum at maturity. They correspond to the definition Type I (a), II (b), III (c), IV (d). e. Emulated fruit pattern used to run the Monte Carlo simulation. These patterns were obtained from the pattern generation software described in. ${ }^{21}$ Dots in Fig. 2e represent fully developed ovaries while circles are random located "IDF vis." 
since it is found by outside the Poisson confidence limit (dotted line $=$ random distribution reference) (Figure 3a,b). The Type IV pattern presented results consistent with Ripley's ${ }^{21}$ definition for a completely randomized distribution (Figure $3 \mathrm{c})^{4}$ and agrees with the random pattern artificially generated for this study (Figure 3d).

In a previous work, analyzing the existing relationships between the visits of pollinators and the generation of IDF $_{\text {vis }}$, we were able to demonstrate the existence of three types of causes by which these fruits would occur. ${ }^{18}$ Within them, the cause of chance, i.e. the non-existence of a predictable factor that generates these products has not been demonstrated or observed.

From the analysis conducted here, it was noted that in a crop for the same year, the generation of $\mathrm{IDF}_{\mathrm{vis}}$ in capitula showed a different distribution pattern. It would be expected that in a hybrid with genetic homogeneity and with a harvest organ such as a capitulum, with high organizational fruit arrangement, the $\mathrm{IDF}_{\text {vis }}$ pattern would be similar in most of them. However, for the same crop cycle it was observed that there are easily quantifiable differences in the $\mathrm{IDF}_{\mathrm{vis}}$ pattern between plants of the same hybrid and between hybrids in the same year. When the observation was repeated in different years, it was even observed that there was a clear tendency to general similar $\mathrm{IDF}_{\mathrm{vis}}$ patterns for the same hybrid.

According to the "non-uniform pollination hypothesis" the observed patterns of $\mathrm{IDF}_{\mathrm{vis}}$ in the mature capitula in this work could be attributable to variation in pollen receipt over the inflorescence flowering period. ${ }^{30-33}$ Specifically, the relatively low seed sets in central areas of the sunflower capitulum as seen in pattern Type I, has usually been attributable to insufficient pollen quantity or pollinators visits. ${ }^{18}$

The availability of resources can vary in both space and time for an individual flower, due to local competition for them. ${ }^{34,35}$ Hence, within a capitulum, resources may be limited for some flowers but not for others. Nevertheless, we do not think this is the case for the peripheral flowers of the sunflower capitulum. It has been observed that at early anthesis stages, recent open flowers, mainly at the capitulum periphery, are not deprived from assimilate supply 8,10 and are the "preferred" ones beginning with fecundation time and up to their ovaries are filled.

Our results agree for the "architectural effects hypothesis" 14,33 which postulated that the observed patterns could be attributable to architectural limitations on the fruit set of the different positions along the shoot, or, in this case, a flat circular surface
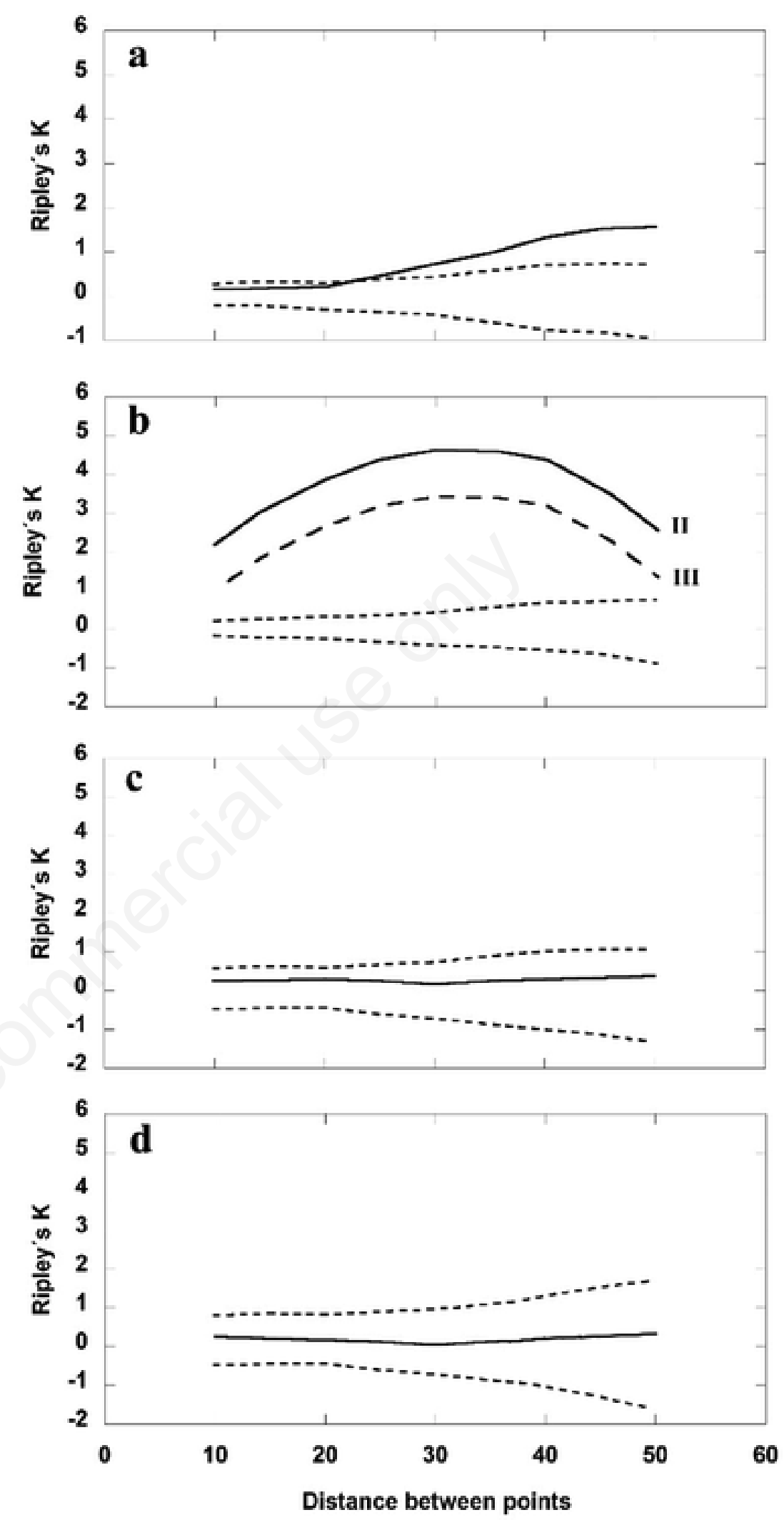

Figure 3. a-c. Index K obtained from the spatial analysis for each type of pattern (Fig. 2) showed that for the scales analyzed, the Types I (Fig. 2a), II (Fig. 2b) and III (Fig. 2c) can be defined as grouped ${ }^{25}$ since it is outside the Poisson confidence limit (random distribution reference) (Fig. 3a-b). The Type IV pattern presented results consistent with the definition of Ripley ${ }^{22}$ for a completely randomized ${ }^{25}$ distribution (Fig. 3c). d. K index from random generated patterns (Fig. 2d) in a simulated fruit pattern in capitula showing the boundary limits after de Monte Carlo ${ }^{28}$ simulation. 


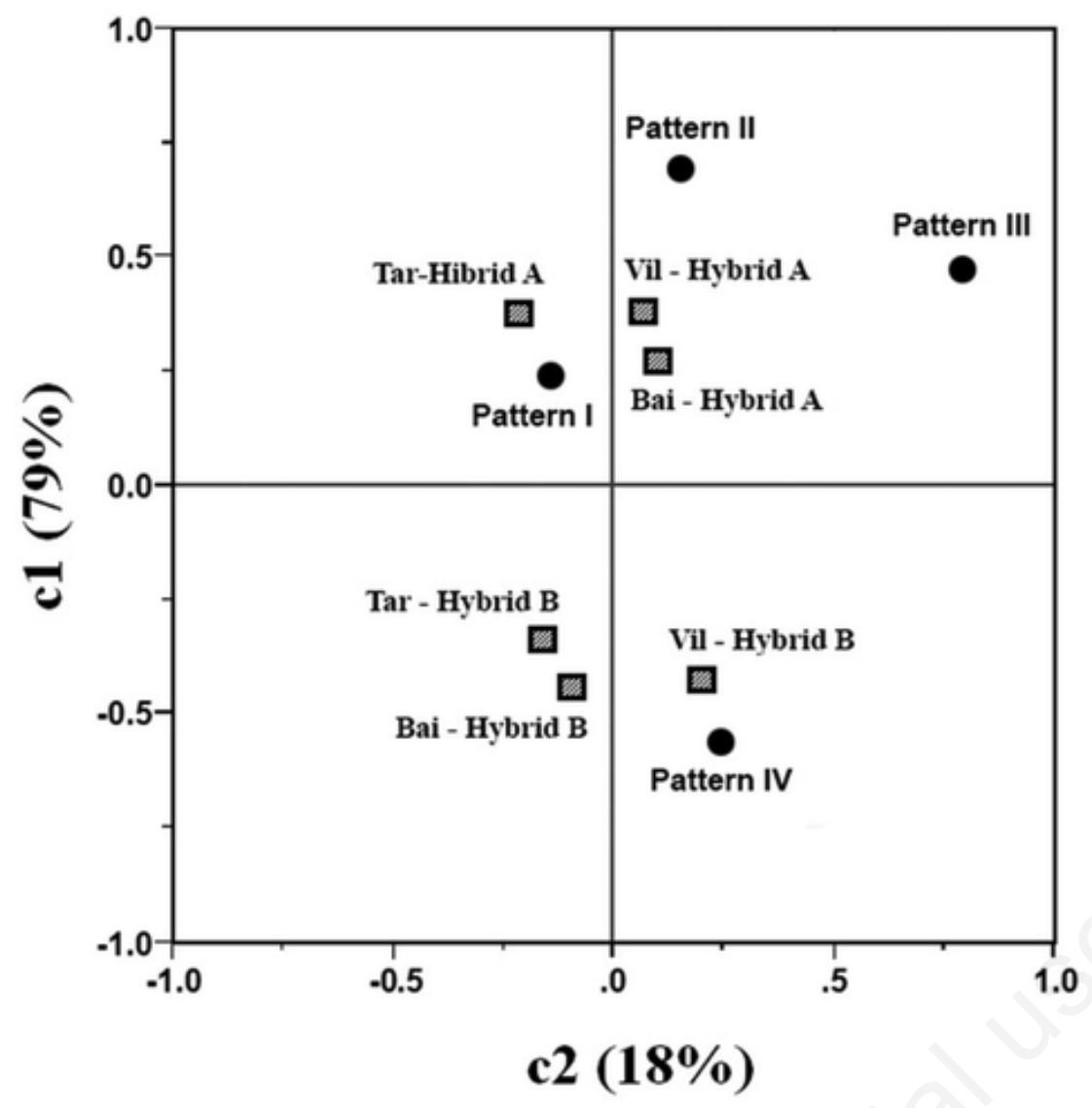

Figure 4. Correspondence analysis: distribution of samples of the two hybrids (A and B) and three experimental sites Colorado river valley (Vii), Bahía Blanca experimental field

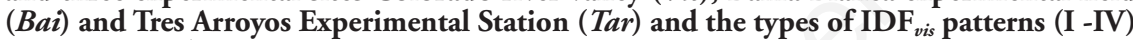
on axes $\mathrm{c} 1$ and $\mathrm{c} 2$.

with finite boundaries. On the one hand, pollen supply could be low in those regions due to the low occurrence of bee visits, but on the other hand, factors related to the floral biology (physiological factors) of the studied genotype might be acting.

In a previous work, ${ }^{18}$ it was found the absence of IDF $(0 \%)$ in areas of the capitulum surface at anthesis covered over $60 \%$ by pollinators. On the other hand, the occurrence of sectors with a fluctuating level of $\mathrm{IDF} \%$ ranging from 5 to $10 \%$ of the total value, would explain that the total IDF generated in that region. Also, in that work, ${ }^{18}$ it was observed a random visit of pollinators that could be associated with this description of random patterns of IDF.

In this paper a different approach is presents, considering the possibility of having a random distribution of IDF $_{\text {vis }}$, which cannot be explained by other causes. However, it was determined that the distribution of $\mathrm{IDF}_{\mathrm{vis}}$ is mostly not random except in the hybrid A with greater self-compatibility, which for all three sites presented the random distribution pattern of IDF $_{\text {vis. }}$.
It was observed that the Type IV pattern (random distribution) was presented in a very low frequency and only for one genotype (hybrid A) in one of the three environments ( Vil) (Figure 4), while in the rest of the genotype $\mathrm{x}$ environment combination there were a greater degree of grouping (patterns Type I, II and III; Figure 4).

It can be concluded that the pattern is non-random and therefore there are intrinsic causes to continue evaluating that define the cause of the $\mathrm{IDF}_{\mathrm{vis}}$ generation.

\section{References}

1. Lindström LI., García ME, Hernández LF. Morphology and distribution of incompletely developed fruits in sunflower (Helianthus annuus L.) capitula. XVI. Intl Sunf Conf Proc Fargo 2004:333-337.

2. Hernández LF, Pellegrini $\mathrm{CN}$, Lindström LI. Prediction of the generation of seedless fruits in the sunflower capitulum (Helianthus annuus L.). XI Latin American Meeting Plant Physiol. Punta del Este, Uruguay; 2001. pp 2325.

3. Birch EB, van der Sandt, JC. Bee pollination of sunflower. XVI. Intl Sunf Conf Procs Mar del Plata, Argentina, ISA; 1985. pp. 255-260.

4. Cantagallo JE, Medan D, Hall AJ. Grain number in sunflower as affected by shading during floret growth, anthesis and grain setting. Field Crops Res 2004;85:191-202.

5. Connor DJ, Hall AJ. Sunflower Physiology, pp. 113-182. In: A.A. Schneiter, [ed.], Sunflower Technol. and Prod., Agron. Ser. 35, ASA, CSSA, SSSA, Madison, WI, USA. 1997.

6. Gillaspy G, Ben-David HW, Gruissem W. Fuits: A developmental perspective. Plant Cell 1993;5:1439-51.

7. Hernández LF, Bellés PM, Bidegain MA, Postemsky PD. Biomechanical proposal as a cause of incomplete seed and pericarp development of the sunflower (Helianthus annuus L.) fruits. Intl J Exp Bot 2018;87:198-208.

8. Alkio M, Grimm E. Vascular connections between the receptacle and empty achenes in sunflower (Helianthus annuus L.). J Exp Bot 2003;54:345-8.

9. Durrieu G, Percie du Sert C, Merrien A. Anatomie du capitule de tournesol consequencessur la nutrition des akenes. XVI. Intl Sunf Conf Procs Mar del Plata, Argentina, ISA; 1985 pp. 7-12.

10. Hernández LF, Orioli GA. Role of different leaves of the sunflower (Helianthus annuus L.) plant during the grain filling period. Turrialba 1991; 41:330-4.

11. Hernández LF, Palmer JH. Incorporation of ${ }^{14} \mathrm{C}$ labeled metabolites into the developing sunflower capitulum. XVI. Intl Sunf Conf Procs Pisa, Italy, ISA; 1992. pp. 564-570.

12. Ashman T-L, Hitchens MS. Dissecting the causes of variation in intra-inflorescence allocation in a sexually polymorphic species, Fragaria virginiana (Rosaceae). Amer J Bot 2000;87:197204.

13. Vaughton G. Nonrandom patterns of fruit set in Banksia spinulosa (Proteaceae): interovary competition within and among inflorescences. Int $\mathrm{J}$ Plant Sci 1993;154:306-13.

14. Strickler K, Vinson JW. Simulation of the effect of pollinator movement on alfalfa seed set. Environ Entomol 2000;29:907-18

15. Halle F, Oldeman RAA, Tomlinson PB. Tropical trees and forests. An architectural analysis. Springer-Verlag, Berlin, 
Heidelberg, 1978.

16. Xia N. Modeling and simulation of fruit setting patterns of the peach Shoot. Intl Conf Cyberworlds 2008. pp. 640-647.

17. Hernández LF. Visit path pattern of the honeybee (Apis mellifera L.) On the sunflower capitulum -correspondence with the location of seedless and incompletely developed fruits. Helia 2008;31:1-16.

18. Astiz V, Iriarte LA, Flemmer A, Hernández LF. Self-compatibility in modern hybrids of sunflower (Helianthus annuus L.). Fruit set in open and self-pollinated (bag isolated) plants grown in two different locations. Helia 2011;34:129-38.

19. Schneiter A, Miller JF. Description of sunflower growth stages. Crop Sci 1981;21:901-3.

20. Hernández LF, Palmer JH. A computer program to create the Fibonacci floret pattern of the sunflower head. XVI. Intl Sunf Conf Procs Novi Sad, Yugoslavia 1988. pp. 150-155.

21. Ripley BD. Modelling Spatial Patterns. 1977. J Royal Stat Soc Ser B 1977; 39:172-212.
22. Getis A, Franklin J. Second-order neighborhood analysis of mapped point patterns. Ecology 1987;68:473-7.

23. Thioulouse J, Chessel D, Dole'dec S, Olivier J-M. ADE-4: a multivariate analysis and graphical display software. Statistics and Comp 1997;7:75-83.

24. Bailey TC, Gatrell AC. Interactive Spatial Data Analysis. Longman, London. 1995.

25. Dale MRT. Spatial Pattern Analysis in Plant Ecology. Cambridge University Press, New York. 1999.

26. Hasse P. Spatial pattern analysis in ecology based on Ripley's K-function: introduction and methods of edge correction. J Veget Sci 1995;6:575-82.

27. Moller J, Waagepetersen RP. Statistical Inference and Simulation for Spatial Point Processes. Chapman and Hall/CRC, New York. 2003.

28. Mast JN, Veblen TT. Tree spatial patterns and stand development along the pine-grassland ecotone in the Colorado Front Range. Can J Forest Res 1999;29: 575-84.

29. Berry PE, Calvo RN. Pollinator limitation and position dependent fruit set in the high Andean orchid Myrosmodes cochleares (Orchidaceae). Plant Syst Evol 1991;174:93-101.

30. Brunet J, Charlesworth D. Floral sex allocation in sequentially blooming plants. Evolution 1995;49:70-9.

31. Thomson JD. Pollination and seed set in Diervilla lonicera (Caprifoliaceae): temporal patterns of flower and ovule development. Amer J Bot 1985;72:73740.

32. Thomson JD. Deployment of ovules and pollen among flowers within inflorescences. Evol Trends Plants 1989;3:65-8.

33. Stephenson AG. The regulation of maternal investment in plants. In: C. Marshall and J. Grace [eds.], Fruit and Seed Production: Aspects of Development, Environmental Physiology and Ecology, Cambridge UniversityPress, Cambridge, UK. 1992. pp. 151-171.

34. Wyatt $\mathrm{R}$. The reproductive biology of Asclepias tuberosa. II. Factors determining fruitset. New Phytol 1981;88: 375-85. 